\title{
Editorial
}

Digestion

Published online: January 10, 2006

\section{Dysplasia and Cancer in Ulcerative Colitis: Too Many Questions, Too Few Answers}

\author{
Geert D'Haens \\ Imelda Gastrointestinal Clinical Research Center, Bonheiden, Belgium
}

The development of dysplasia and cancer is one the most worrisome complications of longstanding inflammatory bowel disease (IBD). Whereas the problem was initially thought to be limited to ulcerative colitis (UC), several reports have highlighted its occurrence in small and large bowel Crohn's disease (CD) as well, even within fistula tracks [1]. The persistent inflammatory triggers probably lead to genetic alterations and malignant degeneration, but the precise pathogenesis of the problem, which appears to be different from the 'classic' adenomacarcinoma sequence, has not been unraveled. The risk of dysplasia and cancer has always been associated with the extent of inflammation in the gastrointestinal tracts and much less with the severity of the disease, an observation which is difficult to understand in view of the presumed pathogenesis. Recent data suggest, however, that the intensity of inflammation may also contribute to trigger malignant degeneration [2]. In addition, several other factors have been suggested as definite or potential risk factors. The presence of cholestatic liver disease as in primary sclerosing cholangitis is undoubtedly associated with an elevated cancer risk. Furthermore, the use of immunomodulators, such as azathioprine/6-mercaptopurine, has been associated with dysplasia and cancer in isolated reports, but this has certainly not been a consistent observation.

The incidence of the problem and the fact that it occurs in young patients warrant a careful search for pre- ventive measures. The paper by Munkholm et al. in this issue of Digestion provides a thorough review of the available literature. Unfortunately, most of the available evidence is based on retrospective observations, personal opinion and speculation about mechanisms of action. Two potential preventive measures, colonoscopic surveillance programs and the permanent use of aminosalicylates, deserve further discussion.

Despite the lack of 'hard' evidence that systematic surveillance is effective to prevent colorectal cancer (CRC), several 'guidelines' recommend its use in routine practice, at least in UC. One has to realize, however, that the majority of dysplasia/cancers are being found at the first 'surveillance' colonoscopy. A bit more convincing are the data from an American survey showing a longer survival in patients with cancer diagnosed during surveillance than in patients outside surveillance [3]. Nonetheless, the overall cost per extra patient-year of survival is gigantic [4]. Fortunately, recent studies by Kiesslich et al. [5] have now demonstrated a significant increase in the yield of surveillance endoscopy by using methylene blue staining (so-called 'chromo-endoscopy'). Centers that routinely use surveillance colonoscopies should apply this technique, be it with or without magnifying endoscopes. This is probably a more rewarding strategy than randomly taking 32 biopsies, given the large inter-observer variability in histological interpretation of dysplasia. Undoubtedly, even more sensitive techniques such regular fecal DNA

\section{KARGER \\ Fax +4161306 1234 E-Mail karger@karger.ch} www.karger.com
(C) 2006 S. Karger AG, Base 0012-2823/06/0731-0009\$23.50/0

Accessible online at: www.karger.com/dig
Geert D'Haens, MD, PhD

Imelda Gastrointestinal Clinical Research Center Imeldalaan 9

BE-2820 Bonheiden (Belgium)

Tel. +32 15505 161, Fax +32 15505 706, E-Mail Geert.Dhaens@imelda.be 
sampling may lead to strategies which could possibly replace the unpleasant and costly endoscopies.

The second 'hot issue' is chemo-prophylactic treatment with aminosalicylates. The authors state that the low incidence of dysplasia/cancer in Denmark could be related to the high use of aminosalicylates in this country, but fail to give numbers on the use of these drugs in other countries to support their statement. In addition, therapeutic algorithms for UC in Denmark are characterized by a low threshold for colectomy, as was reported by Langholz et al. [6] in several incidental cohorts. The most convincing though retrospective observation, so far, comes from a study by Eaden et al. [7] in the UK. More than 100 patients with UC and CRC were studied in a case-control analysis. Regular intake of aminosalicylates reduced the CRC risk independently by more than $75 \%$ ! The results showed a reduced incidence of dysplasia/cancer in patients using at least $1.2 \mathrm{~g}$ of 5-ASA daily and in those seeing their doctor at least twice per year. Several other studies [8] and a meta-analysis by Velayos et al. [9] have since confirmed the same trend.

Several questions arise with regard to mesalazine and the prevention of dysplasia/CRC risk: Is the chemo-pre- ventive effect a consequence of suppression of inflammation (in which case other drugs such as azathioprine could also be chemo-preventive), or is this a specific action of aminosalicylates? If the latter is the case, aminosalicylates should also be given to patients with longstanding CD, certainly in those with Crohn's colitis. If the effect is indeed dose-dependent, as the authors suggest, the use of preparations with higher 5-ASA concentrations (such as the 2-gram Pentasa sachets or the 1.2-gram Shire tablets) may increase compliance and the biological effect. In addition, several other treatment options such as the widespread use of ursodeoxycholic acid in IBD patients without primary sclerosing cholangitis should be studied more extensively.

In conclusion, despite suggestive indirect evidence, the lifelong use of aminosalicylates in all patients with IBD does not seem to be warranted at this point in time. Since it will be hard to set up (and complete) prospective studies at a sufficient scale to convincingly prove the chemo-preventive effects of 5-ASA, larger (retrospective) series should at least be looked at to finally deliver a scientifically satisfactory answer and set up evidence-based recommendations.

\section{References}

1 Choi PM, Zelig MP: Similarity of colorectal cancer in Crohn's disease and ulcerative colitis: implications for carcinogenesis and prevention. Gut 1994;35:950-954.

2 Rutter M, Saunders B, Wilkinson K, Rumbles S, Schofield G, Kamm M, Williams C, Price A, Talbot I, Forbes A: Severity of inflammation is a risk factor for colorectal neoplasia in ulcerative colitis. Gastroenterology 2004;126:451459 .

3 Choi PM, Nugent FW, Schoetz DJ Jr, Silverman ML, Haggitt RC: Colonoscopic surveillance reduces mortality from colorectal cancer in ulcerative colitis. Gastroenterology 1993; 105:418-424.
4 Provenzale D, Wong JB, Onken JE, Lipscomb $\mathrm{J}$ : Performing a cost-effectiveness analysis: Surveillance of patients with ulcerative colitis. Am J Gastroenterol 1998;93:872-880.

5 Kiesslich R, Fritsch J, Holtmann M, Koehler HH, Stolte M, Kanzler S, Nafe B, Jung M, Galle PR, Neurath MF: Methylene blue-aided chromoendoscopy for the detection of intraepithelial neoplasia and colon cancer in ulcerative colitis. Gastroenterology 2003;124:880 888.

6 Langholz E, Munkholm P, Davidsen M, Binder V: Course of ulcerative colitis: analysis of changes in disease activity over years. Gastroenterology 1994;107:3-11.
7 Eaden J, Abrams K, Ekbom A, Jackson E, Mayberry J: Colorectal cancer prevention in ulcerative colitis: a case-control study. Aliment Pharmacol Ther 2000:145-153.

8 Ullman T, Croog V, Harpaz N, Itzkowitz S, Kornbluth A: Preventing neoplastic progression in ulcerative colitis. Gastroenterology 2003;124(suppl 1):A242.

9 Velayos FS, Terdiman JP, Walsh JM: Effect of 5-aminosalicylate use on colorectal cancer and dysplasia risk: a systematic review and metaanalysis of observational studies. Am J Gastroenterol 2005; 100:1345-1353. 